Wafa'a M. Eyaid $\cdot$ Mark V. Clough $\cdot$ Holly Root

Kathleen M. Scott $\cdot$ Mary Kay McCormick $\cdot$ Xue Zhang

Nikolai A. Lisitsyn • William G. Kearns

Clair A. Francomano · Julia E. Richards · Iain McIntosh

\title{
Physical mapping of the nail patella syndrome interval at 9q34: ordering of STSs and ESTs
}

Received: 6 July 1998 / Accepted: 10 July 1998

W.M.E. and M.V.C. contributed equally to this work

W. M. Eyaid · M. V. Clough · W. G. Kearns · I. McIntosh ( Center for Medical Genetics, Johns Hopkins University, 600 North Wolfe Street, Blalock 1012G, Baltimore, MD 21287-4922, USA e-mail: imcintos@welchlink.welch.jhu.edu, Tel.: +1 4109557948 , Fax: +14106142522

H. Root

Genome Technology Branch, National Human Genome Research Institute, National Institutes of Health, Bethesda, MD 20892, USA

K. M. Scott · J. E. Richards

Department of Ophthamology,

University of Michigan Ann Arbor, MI 48105, USA

M. K. McCormick ${ }^{1}$

Molecular Neurogenetics Unit, Massachusetts General Hospital, Charlestown, MA 02129, USA

X. Zhang 2 - N. A. Lisitsyn

Department of Genetics, University of Pennsylvania

School of Medicine, Philadelphia, PA 19104 USA

W. G. Kearns

Department of Pediatrics, East Virginia Medical School, Norfolk, VA 23510, USA

\section{A. Francomano}

Medical Genetics Branch, National Human Genome Research

Institute, National Institutes of Health, Bethesda, MD 20892, USA

J. E. Richards

Department of Epidemiology, University of Michigan,

Ann Arbor, MI 48105, USA

${ }^{1}$ Present address:

AxyS Pharmaceuticals, La Jolla, CA 92037, USA

${ }^{2}$ Present address:

X. Zhang, Department of Medical Genetics,

China Medical University, Shenyang, China
Nail patella syndrome (NPS, MIM 161200) or onychoosteodysplasia is an autosomal dominant, pleiotropic disorder characterized by nail dysplasia, absent or hypoplastic patellae, exostoses ("horns") of the ilia, dysplasia of the elbows, and in some cases, nephropathy (Beals and Eckhardt 1969). Genetic linkage between the nail patella syndrome and the $\mathrm{ABO}$ blood group, with an estimated recombination fraction of 0.1 , was the third autosomal linkage relationship to be established in humans (Renwick and Lawler 1955). The increasing density of genetic markers has allowed the positioning of the NPS locus within a $1-2 \mathrm{cM}$ interval between D9S60 and AK1 with maximal two-point LOD scores at D9S112 (LOD=27.0, $\theta=0.00)$ and $\mathrm{D} 9 \mathrm{~S} 315$ $(\mathrm{LOD}=22.0, \theta=0.00$; McIntosh et al. 1997). Study of additional NPS families has further reduced the interval to that between D9S315 and D9S2172 (data not shown). In order to isolate the gene mutated in persons with NPS, the physical mapping of this region has been initiated.

First, the information available from the Whitehead Institute was used to identify Centre d'Etude du Polymorphisme Humain (CEPH) yeast artificial chromosomes (YACs) from the interval (URL: http://www.genome.wi.mit.edu/cgi-bin/ contig/phys_map). This enabled the establishment of a contig from D9S117 to D9S266 (Fig. 1) but did not include either D9S315 or D9S112 (previously shown to be the closest markers to NPS; McIntosh et al. 1997) or any further telomeric markers. Screening of additional YAC libraries identified a series of clones that established a contig across the NPS interval, as defined by recombination events (data not shown), and, secondly, a contig from D9S117 to AK1 with only three small gaps (two of which separate D9S918 from flanking markers; Fig. 1).

Analysis of the human gene map (URL: http://www. ncbi.nlm.nih.gov/SCIENCE96/) identified 94 cDNAs positioned between D9S282 and D9S260 (telomeric of AK1; McIntosh et al. 1997). Except for those representing genes of known function deemed incompatible with a role in NPS and those mapped outwith the candidate interval in the Whitehead database, these cDNAs were positioned on the physical map. Out of 69 tested, 13 cDNAs were positioned on the map relative to other markers (Fig. 1), none lying 


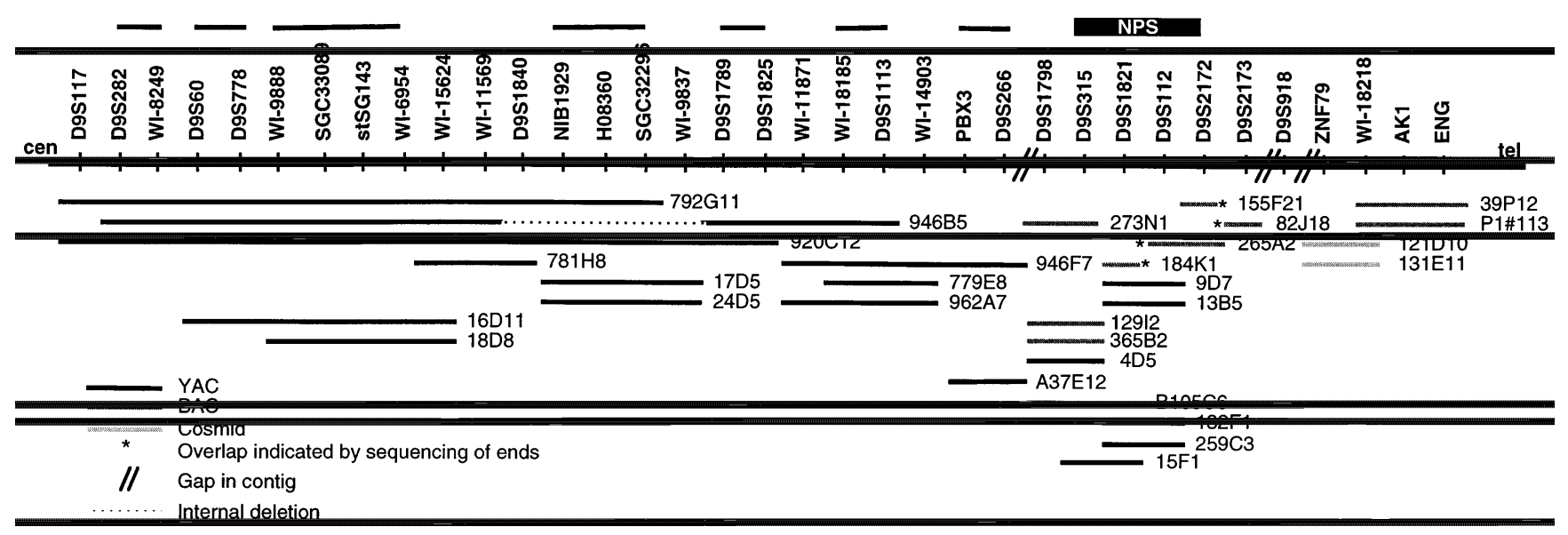

Fig. 1 Physical map of the D9S117-ENG interval. Lines above the loci group those that cannot be ordered relative to each other. The NPS interval is indicated by the thick bar. The dashed line within YAC 946B5 represents a deletion predicted by STS mapping and confirmed by fiber-fluorescence in situ hybridization (data not shown). STSs and ESTs were selected from the databases on the basis of mapped position. Primers were obtained from Research Genetics (Hunstville, Ala.) or were designed from the sequences in Genbank. YACs 792G11, 946B5, 920C12, 781H8, 946F7, 779E8, and 962A7 from the CEPH library were selected on the basis of the published map (Chumakov et al. 1995) and purchased from Research Genetics. YACs 16D11, 18D8, 17D5, 24D5, 9D7, and 13B5 from a chromosome-9-specific library (McCormick et al. 1993), YACs 259C3 and $132 \mathrm{~F} 1$ from the ICI library (Anand et al. 1990), and A37E12 and B105C6 from the Washington University library (Brownstein et al. 1989) were selected by the polymerase chain reaction (PCR) with primers for loci within or around the NPS interval. BACs 129I2, 365B2, 273N1, 184K1, 265A2, 155F21, 82J18, and 39P12 were identified by PCR screening of Human BAC Pools Release II from Research Genetics. Cosmids were selected from a flow-sorted chromosome-9-specific library by PCR screening (M. K. McCormick, unpublished). YAC 15F1 and P1\#113 were gifts from Claire Shovlin

within the NPS interval. A further three out of 8 cDNAs in dbEST that had been localized to the $9 \mathrm{q} 34$ region by radiation-hybrid mapping (URL: http://www.ncbi.nlm.nih.gov/ $\mathrm{XREFdb/)} \mathrm{were} \mathrm{placed} \mathrm{on} \mathrm{the} \mathrm{map.} \mathrm{Again,} \mathrm{none} \mathrm{mapped}$ within the NPS interval.

Thus, the minimal genetic interval has been established for the NPS gene and this interval has been covered by a contig of YAC and bacterial artificial chromosome (BAC) clones. These resources permit the positional cloning of the NPS gene. Since completion of the work described above, the NPS gene has been identified as that encoding the transcription factor LMX1B (Chen et al. 1998; Dreyer et al. 1998). We have subsequently confirmed the localization of LMX1B within the candidate interval on BACs $155 \mathrm{~F} 21$ and $265 \mathrm{~A} 2$.

Acknowledgements The authors would like to thank the NPS families for their participation in this study, S. Cutone and M. Rutter for technical assistance, and Dr. Danilo A. Tagle for helpful discussions. This work was supported by grants from the National Institutes of Health (AR44702 to I.M., CA64534 to N.A.L., and EY09580 and EY11761 to J.E.R.), the Division of Intramural Research, NHGRI and The King Fahad Hospital National Guard - Health Affairs for Saudi Arabia (W.M.E.). The experiments described in this paper comply with the current laws of United States.

\section{References}

Anand R, Riley JH, Butler R, Smith JC, Markham AF (1990) A 3.5 genome equivalent multi access YAC library: construction, characterization, screening and storage. Nucleic Acids Res 18:1951-1956

Beals RK, Eckhardt AL (1969) Hereditary onycho-osteodysplasia (Nail-patella syndrome). J Bone Joint Surg Am 51:505-515

Brownstein BH, Silverman GA, Little RD, Burke DT, Korsmeyer SJ, Schlessinger D, Olson MV (1989) Isolation of single-copy human genes from a library of yeast artificial chromosome clones. Science 244:1348-1351

Chen H, Lun Y, Ovchimnikov D, Kokubo H, Oberg KC, Pepicelli CV, Gan L, Lee B, Johnson RL (1998) Limb and kidney defects in $L m x l b$ mice suggest an involvement of $l m x l b$ in human nail-patella syndrome. Nat Genet 19:51-55

Chumakov IM, Rigault P, Le Gall I, Bellanné-Chantelot C, Billault A, Guillou S, Soularue P, Guasconi G, Poullier E, Gros I, Belova M, Sanbucy J-L, Susini L, Gervy P, Gilbert F, Beaufils S, Bui H, Massart C, De Tand M-F, Dukasz F, Lecoulant S, Ougen P, Perrot V, Saumier M, Soravito C, Bahouayila R, Cohen-Akenine A, Barillot E, Bertrand S, Codani J-J, Caterina D, Georges I, Lacroix B, Lucotte G, Sahbatou M, Schmit C, Sangouard M, Tubacher E, Dib C, Fauré S, Fizames C, Gyapy G, Millasseau P, Nguyen S, Muselet D, Fvignai A, Morisette J, Menninger J, Lieman J, Desai T, Banks A, Bray-Ward P, Ward D, Hudson T, Gerety S, Foote S, Stein L, Page DC, Lander ES, Weissenbach J, Le Paslier D, Cohen D (1995) A YAC contig map of the human genome. Nature 377 (Suppl):175-297

Dreyer SD, Zhou G, Baldini A, Winterpacht A, Zabel B, Cole W, Johnson RL, Lee B (1998) Mutations in LMX1B cause abnormal skeletal patterning and renal dysplasia in nail patella syndrome. Nat Genet 19:47-50

McCormick MK, Buckler A, Bruno W, Campbell E, Shera K, Torney D, Deaven L, Moyzis R (1993) Construction and characterization of a YAC library with a low frequency of chimeric clones from flow-sorted human chromosome 9. Genomics 18:553-558

McIntosh I, Clough MV, Schäffer AA, Puffenberger EG, Horton VK, Peters K, Abbott MH, Roig CM, Cutone S, Ozelius L, Kwiatkowski DJ, Pyeritz RE, Brown LJ, Pauli RM, McCormick MK, Francomano CA (1997). Fine mapping of the nail patella syndrome locus at 9q34. Am J Hum Genet 60:133-142

Renwick JH, Lawler SD (1955) Genetical linkage between the ABO and nail-patella loci. Ann Hum Genet 19:312-331 